\title{
Risk evaluation of land subsidence and its application to metro safety operation in Shanghai
}

\author{
J. Liu, H. Wang, and X. Yan \\ Shanghai Institute of Geological Survey, Shanghai 200072, China \\ Correspondence to: J. Liu (dabao_0323@163.com)
}

Published: 26 November 2015

\begin{abstract}
Based on sufficiently investigating characteristics and risk connotation of land subsidence, a risk evaluation index system for land subsidence disaster is established, which is combined with the sensitivity feature of the hazard bearing body to land subsidence. An appropriate evaluation method system is established by using an improved fuzzy analytic hierarchy process method. So risk evaluation is developed for providing theoretical basis and technical support for the regional management of land subsidence prevention and control. On this basis, as a case of Shanghai metro, firstly, the paper studies the identifying risk sources of the metro. According to metro linear characteristics, external indexes of representing subsidence risk are obtained. Studying the subsidence risk of the metro, relevant achievement has provided the technical basis for daily main monitoring, early warning and work arrangement.
\end{abstract}

\section{Introduction}

Shanghai will has been built to become the world's economic, financial, trade and shipping center, but it is inhibited by the concentration of population and poor resources. The combination of high-intensity exploitation of land and water resources and a susceptible geological environment makes this rigion prone to land subsidence problems. Specifically, the thick Quaternary overburden whose structure is very soft produces land subsidence by means of imperceptible compression deformation from the influence of natural and artificial factors. Land subsidence does serious harm to the sustainable development of the society and the economy. At present, the average cumulative subsidence in the inner city of Shanghai is generally greater than 0.6 meters, the maximum cumulative subsidence tends to be close to 3 meters, and the height of the inner city is lower than the average elevation of the entire city.

In recent years, Shanghai has further improved its mechanismsfor subsidence prevention and treatment. In particular, groundwater exploitation and artificial recharge management was continually strengthened, and land subsidence monitoring and control capabilities were continually improved. The magnitude of subsidence and its scope of influence has been gradually reduced, but the deep confined aquifer's large cone of depression caused by the long-term over exploitation has influenced land subsidence for a long time. Then after a superposition of other factors such as the deep foundation dewatering and drainage pit, the number of land subsidence cones have gradually increased, the resulting change of equal distance in land subsidence cone areas were more significant, and the nonuniformity of land subsidence has increased year by year. This brought new challenges for the management of land subsidence prevention and control.

This paper introduces the risk evaluation and management method, which is applied to the management of land subsidence prevention and control. Risk evaluation and management is a new subject in the study of geological disasters. Domestic and foreign literature regarding tunnel, landslide and debris flow risk evaluation is well established (Brabb, 1984; Woude and Jonker, 2003; Yoo Chungsik et al., 2006). However, only a few studies exist on the theoretical aspect of land subsidence risk evaluation (Hu et al., 2008; Yu et al., 2008; Chen et al., 2013, 2014). 


\section{Risk evaluation of land subsidence}

\subsection{Risk evaluation indexes of land subsidence}

The risk degree of land subsidence mainly depends on two conditions. One is the dynamic conditions of land subsidence, including geological conditions (the distribution of aquifer, the thickness and structure of soft soil layer, etc), topography (landform, terrain elevation, etc), man-made geological dynamic activities (underground water exploitation, engineering construction, etc). Normally, the ampler dynamic conditions of land subsidence are, the intenser land subsidence disaster activities become. When the damages caused by land subsidence are more serious, the risk of land subsidence is greater. The other is the economic vulnerability of human society. That is the resistant and recoverable ability of life, property and various economic activities in the disaster areas, which includes the population density, the residential environment, the land-use type, the investment for disaster prevention and reduction, etc. Two aspects abovementioned are named for hazard and vulnerability respectively. They determine the risk degree of land subsidence.

The hazard of land subsidence refers to the occurrence probability and danger degree of land subsidence in a certain area and a certain period of time. It is evaluated quantificationally by using $\mathrm{H}$. The evaluation factors of hazard include geological conditions, topography, geological dynamic activities, scale of geological hazard, the occurrence probability, growth rate, etc.

The vulnerability of land subsidence refers to the probability of suffered damage and the difficult of damage caused by land subsidence. This concept implies the ability to cope with the land subsidence disaster which the human society and the development level of economic technical reply. It is evaluated quantificationally by using $V$.

According to the hazard evaluation and the vulnerability evaluation of land subsidence, the final results of the risk evaluation of land subsidence provide basic data for monitoring, forecasting and controlling the land subsidence, and offer decision-making information for the government departments.

\subsection{Risk evaluation method of land subsidence}

According to the current basic data of land subsidence and social economic in Shanghai, the fuzzy comprehensive evaluation model is established by using the improved fuzzy analytic hierarchy process method (Csutora and Buckley, 2001; Feng, 2007). Compared to the traditional analytic hierarchy process, this method not only solves the problem of the consistency of judgment matrix but also overcomes the fuzziness and the distribution difficulty of the factor's weight. The specific calculation steps are as follows.

1. Decision on the evaluation factors. Based on the analysis of the influencing factors and the actual monitoring data, the evaluation factors are selected and formed the factor set.

$$
U=\left\{u_{1}, u_{2}, \ldots, u_{n}\right\}
$$

2. Establishing evaluation collection. The land subsidence risk evaluation set is assumed. Its levels of values range are between 0 and 1 . Specific division is five grades including very low, low, medium, high and very high.

$$
V=\left\{v_{1}, v_{2}, \ldots, v_{m}\right\}
$$

3. Determining the single factor evaluation matrix.

$$
R=\left(r_{i j}\right)_{n \times m}(i=1,2, \ldots, n ; j=1,2, \ldots, m)
$$

where $r_{i j}$ is the membership grade that the index $r_{j}$ was assessed $v_{j}$. For example, the factor "land subsidence susceptibility" may be considered to the "low" grade by twenty percent of experts and the "medium" grade by eighty percent of experts. Then twenty percent and eighty percent respectively refer to the membership grade of "low" and "medium".

4. Using the improved analytic hierarchy process (AHP) to determine the weight vector $W$.

$$
W=\left\{w_{1}, w_{2}, \ldots, w_{n}\right\}
$$

First, established the priority relation matrix.

$f_{i j}=\left\{\begin{array}{l}0.5, s(i)=s(j) \\ 1.0, s(i)>s(j), s_{i} \text { and } s_{j} \text { showed the relative } \\ 0 . s(i)<s(j)\end{array}\right.$ importance degree of factor $u_{i}$ and $u_{j}$. Fuzzy complementary matrix $F=\left(f_{i j}\right)_{n \times m}$ is obtained based on the analysis of the measured data of land subsidence and its influencing factors. Then the sum method of matrix rows $e_{j}=\sum_{j=1}^{n} f_{i j}$, and the following mathematical manipulation are implemented, $e_{i j}=\frac{\left(e_{i}-e_{j}\right)}{2(n-1)}+0.5$. The complementary judgment matrix $E=\left(e_{i j}\right)_{n \times n}$ is changed into a reciprocal matrix $D=\left(d_{i j}\right)_{n \times n}$ by using the transformation formula $d_{i j}=\frac{e_{i j}}{e_{j i}}$.

The sum normalization method is used to obtain the ordering vector.

$$
\begin{aligned}
W^{(0)}= & \left(w^{1}, w^{2}, \ldots, w^{n}\right)^{T}= \\
& \left(\frac{\sum_{j=1}^{n} d_{1 j}}{\sum_{i=1}^{n} \sum_{j=1}^{n} d_{i j}}, \frac{\sum_{j=1}^{n} d_{2 j}}{\sum_{i=1}^{n} \sum_{j=1}^{n} d_{i j}}, \ldots, \frac{\sum_{j=1}^{n} d_{n j}}{\sum_{i=1}^{n} \sum_{j=1}^{n} d_{i j}}\right)
\end{aligned}
$$

Regarded the ordering vector $W^{(0)}$ as an eigenvalue method to solve the ordering vector with higher 
accuracy $W^{(k)}$, the paper inputs the initial value $\alpha^{(0)}=W^{(0)}=\left(\alpha_{01}, \alpha_{02}, \cdots, \alpha_{0 n}\right)^{T}$, uses the iterative formula $\alpha^{k+1}=E \alpha^{k}$, seeks the eigenvalue $\alpha^{k+1}$, and finds the infinite norm $\left\|\alpha^{k+1}\right\|_{\infty}$ of $\alpha^{k+1}$. If $\left|\left\|\alpha^{k+1}\right\|_{\infty}-\left\|\alpha^{k}\right\|\right|<\varepsilon$, the $\left\|\alpha^{k+1}\right\|_{\infty}$ is the largest eigenvalue $\lambda_{\max }$, and the $\alpha^{k+1}$ is used for normaliczation process $\quad \alpha^{k+1}=\left(\frac{\alpha_{k+1,1}}{\sum_{i=1}^{n} \alpha_{k+1, i}}, \frac{\alpha_{k+1,2}}{\sum_{i=1}^{n} \alpha_{k+1, i}}, \cdots, \frac{\alpha_{k+1, n}}{\sum_{i=1}^{n} \alpha_{k+1, i}}\right)$. The obtained vector $W^{(k)}=\alpha^{k+1}$ becomes the ordering vector and iterated is over. Otherwise, this method regardes the vector $\alpha^{k}=\alpha^{k+1} /\left\|\alpha^{k+1}\right\|_{\infty}$ as a new initial value, and iterates again, finally the obtained $W^{(k)}$ serves as the weight allocation vector $W$.

5. Fuzzy comprehensive evaluation.

$V=W \times R$

6. Fuzzy vector uniformization. The evaluation set $V=$ $\left\{v_{1}, v_{2}, \ldots, v_{m}\right\}$ is assigned one to five, then the corresponding evaluation results are divided into five levels.

7. The hazard evaluation and the vulnerability evaluation are carried out through the fuzzy comprehensive evaluation, then the risk degree can be calculated by the next formula.

$R($ risk $)=H($ hazard $) \times V($ vulnerability $)$

\subsection{Risk evaluation of land subsidence}

1. Hazard evaluation of land subsidence

Through analyzing the development mechanism, the incubation conditions, the monitoring results and other factors of land subsidence, the indexes including land subsidence susceptibility, historical disaster intensity, sedimentation rate and ground elevation are choosen to evaluate the hazard of land subsidence. The single factor evaluation map is compiled based on the land subsidence hazard evaluation of each single index evaluation. Then the basic properties of all kinds of influencing factors are extracted through the space intersection analysis. The above method is used for evaluating the hazard (Fig. 1).

It can be seen from the evaluation results that land subsidence in Shanghai mainly locates in medium-hazard areas. High hazard and very high hazard areas are mainly distributed in the central city and the local area of Jiading district and Jinshan district which are adjacent to Jiangsu province and Zhejiang province. Low hazard and very low hazard areas are mainly distributed in the local area of Fengxian district, Qingpu district and other districts.
2. Vulnerability evaluation of land subsidence

Due to the difficulty of acquiring the data of suffering disasters zone and the easiness of obtaining the regional social and economic data based on the administrative unit (district, county), the vulnerability evaluation indexes of land subsidence mainly consider the social and economic statistic (GDP, population density, proportion of land for construction), linear infrastructure influenced by land subsidence (flood control wall, metro, water supply network, elevated road), disaster prevention and reduction investment in the past (monitoring and control facilities). It can be seen from the evaluation results (Fig. 2) that the vulnerability of land subsidence reflects the comprehensive characteristics about the development level of regional economic and land subsidence.

\section{Risk evaluation of land subsidence}

Based on hazard and vulnerability evaluation of land subsidence, risk zoning map of land subsidence in Shanghai is compiled after dividing risk grade (Fig. 3). The spatial distribution characteristics can be seen from the evaluation results. The risk of land subsidence shows three-level system characteristics which revolves around the inner city of Shanghai: the very high risk region of land subsidence mainly locates in the inner city, the high to medium risk region of land subsidence mainly locates in the suburban area and the low to very low risk region of land subsidence mainly locates in the far-suburban area.

\section{Regional management of land subsidence prevention and control}

\subsection{Division of land subsidence prevention and control}

According to the current development situation of land subsidence and the development trend of regional social and economic, the regional management of land subsidence prevention and control can be realized on the basis of the land subsidence risk evaluation. Combined two-level management system of land subsidence prevention and control, the unit is identified as the administrative region which are city and district in Shanghai. It also reads the urban and rural planning for reference. It can enhance the management level of land subsidence prevention and control (Fig. 4).

1. Emphasis prevention area of land subsidence (area I)

It is divided into two subregions that are area $I_{1}$ and area $I_{2}$. Area $I_{1}$ is the inner city inside the outer ring road where the serious land subsidence disaster has happened. In this area, the situation of flood control is severe, inhomogeneous land subsidence is obvious, and safe operation of grave projects are affected greatly. 


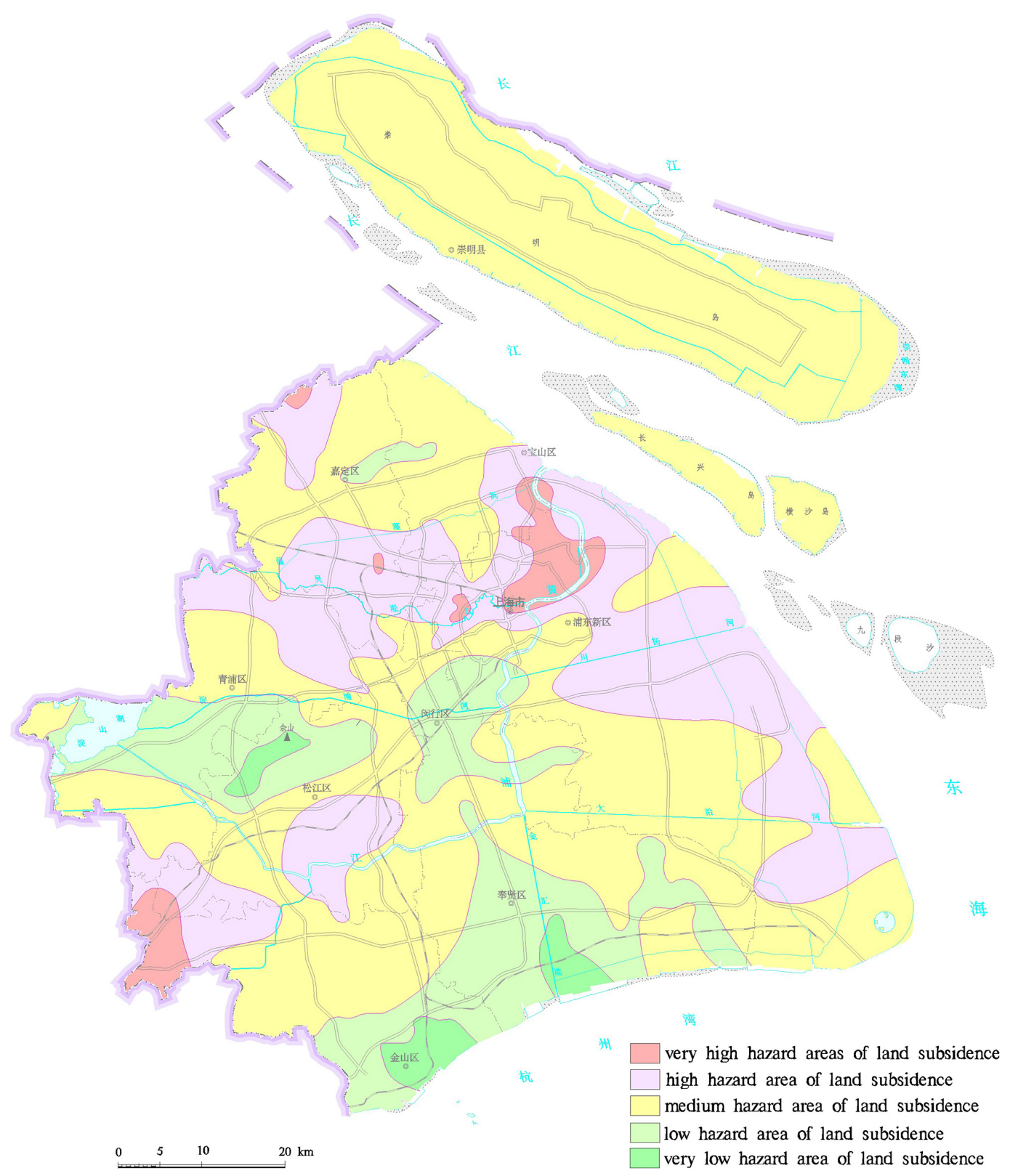

Figure 1. Hazard evaluation of land subsidence in Shanghai.

Area $\mathrm{I}_{2}$ includes Pudong new district and Hongqiao area outside the outer ring road. With the adjustment and implementation of urban master planning, in recent evolution of land subsidence presents an aggravating tendency. Because of engineering construction, some land subsidence centers have formed, for instance, Hongqiao, Sanlin, etc. In area $I_{2}$ the phenomenon of inhomogeneous land subsidence is serious, which seriously influences infrastructure safety operation including metro, maglev trains, flood control wall, etc.

2. Second-emphasis prevention area of land subsidence (area II)
Area II includes Baoshan district, Jiading district and Minhang district except for area I. In this area land subsidence is medium, however, as the future development region of urban master planning, the influence of engineering for land subsidence should not be neglected. In history, underground water level of major exploiting aquifer (the fourth confined aquifer) in this erea is very low, and in some parts of area groundwater cones are due to the exploitation of underground water in neighboring province.

3. General prevention area of land subsidence (area III) 


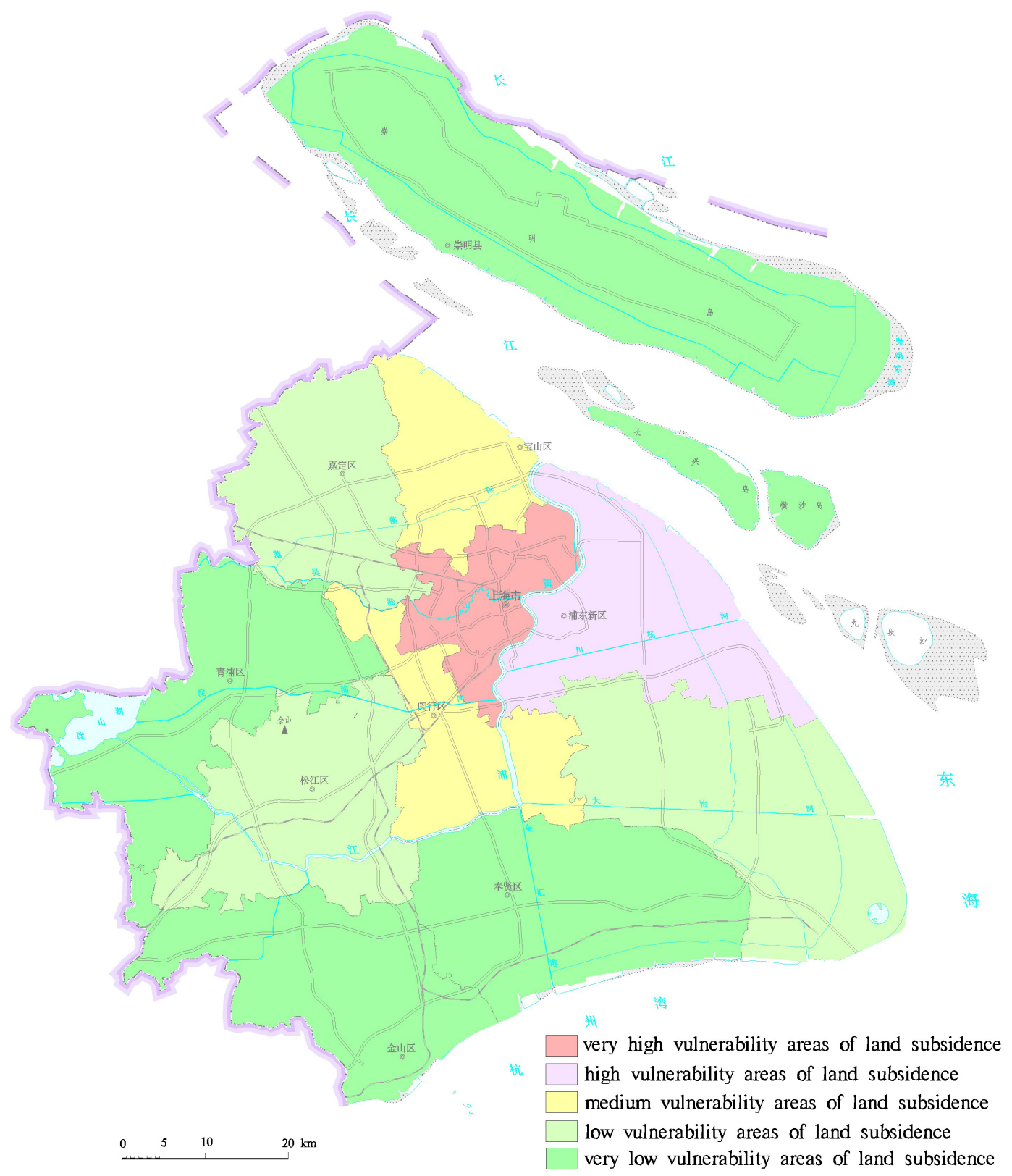

Figure 2. Vulnerability evaluation of land subsidence in Shanghai.

Area III Includes Fengxian district, Songjiang district, Jinshan district, Qingpu district and Chongming county. In this area the overall development intensity is low, and land subsidence is medium or low, but land subsidence is still outstanding in some areas because of the exploitation of underground water in neighboring province, especially, seawall in north shore of Hangzhou Bay.

\subsection{Control objectives of land subsidence regional prevention and control}

1. Control objectives of emphasis prevention area of land subsidence (area I)

In emphasis prevention area of land subsidence (area $I_{1}$ ), by the end of 2015 , the annual average amount of land subsidence will control within $7 \mathrm{~mm}$, the groundwater table of the fourth confined aquifer groundwater table will return to $-12 \mathrm{~m}$ and the impact of asymmetrical land subsidence will be further reduced. In emphasis prevention area of land subsidence (area $\mathrm{I}_{2}$ ), by the end 


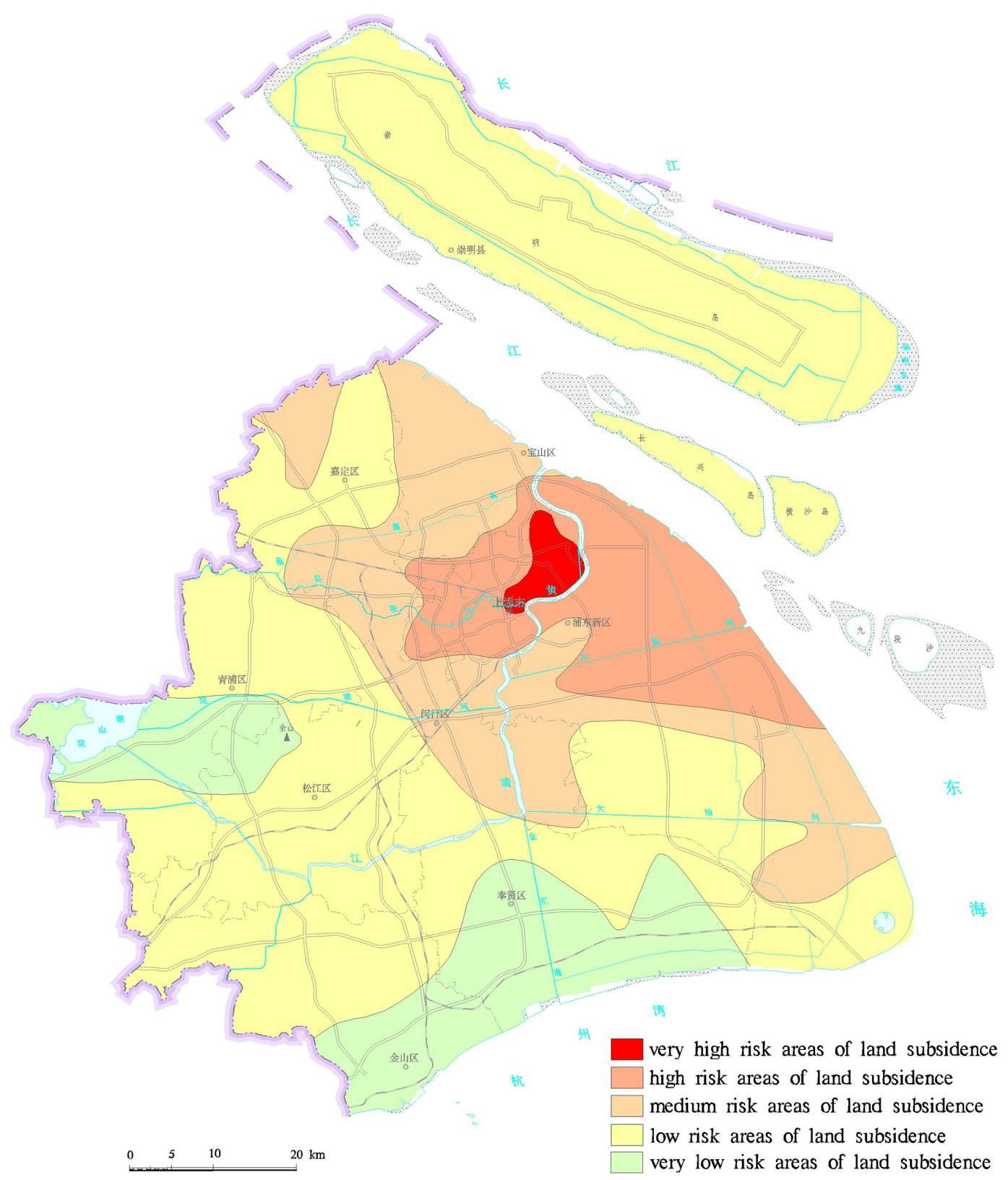

Figure 3. Risk evaluation of land subsidence in Shanghai.

of 2015, the annual average amount of land subsidence will control within $10 \mathrm{~mm}$, the groundwater level will lift steadily and the impact of asymmetrical land subsidence will be relieved gradually.

2. Control objectives of second-emphasis prevention area of land subsidence (area II)

By the end of 2015, the annual average amount of land subsidence will control within $6 \mathrm{~mm}$ and the confined aquifer groundwater funnel along the lifeline engineering will be eliminated basically.
3. Control objectives of general prevention area of land subsidence (area III)

By the end of 2015, the annual average amount of land subsidence will control within $5 \mathrm{~mm}$ and the confined aquifer groundwater cone triggered by the exploitation of groundwater will be eliminated actively. 


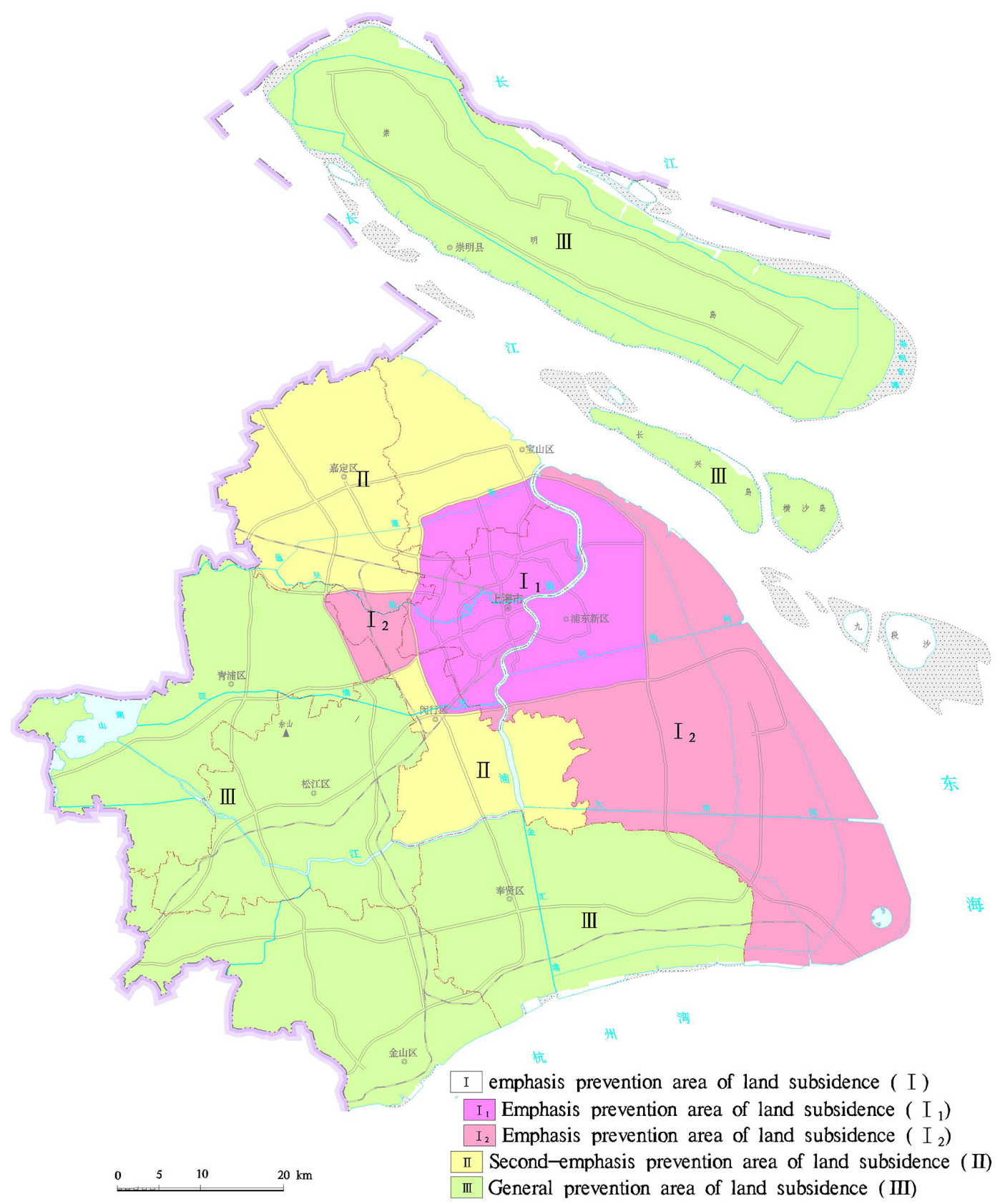

Figure 4. Land subsidence regional prevention and control management.

\subsection{Measures of land subsidence regional prevention} and control

1. Measures of emphasis prevention area of land subsidence (area I)

In emphasis prevention area of land subsidence (area $\mathrm{I}_{1}$ ), many measures will have been taken to prevent and control land subsidence, such as the stricter management of groundwater exploitation and recharge, the special recharge in shallow aquifer and the early warning mechanism for the track traffic, flood wall and other lifeline engineering. In emphasis prevention area of land subsidence (area $I_{2}$ ), many measures will have been taken to prevent and control land subsidence, such as the compression of groundwater exploitation, the distensible size of artificial recharge, the intensive monitoring and management of land subsidence caused by deep foundation pit and other construction activities, the enhanced subsidence monitoring of the metro, the maglev train, the sea wall, and other lifeline engineerings. 


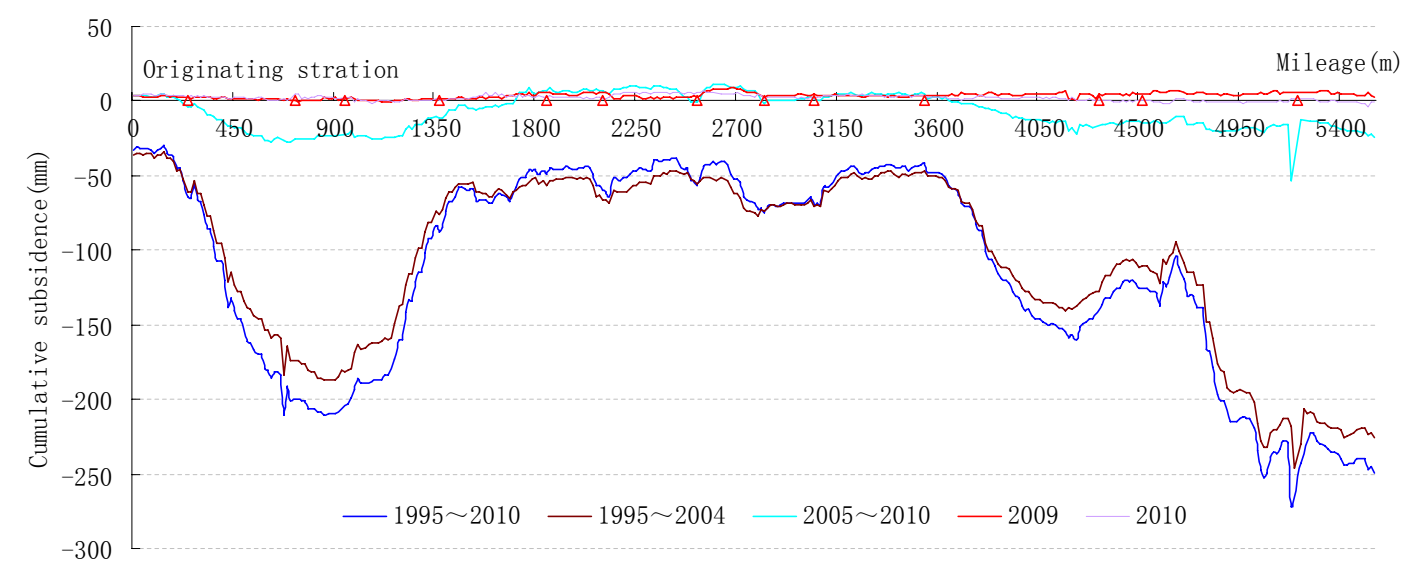

Figure 5. The cumulative subsidence curve of metro in each stage.

Table 1. Evaluation indexes system of metro subsidence.

\begin{tabular}{ll}
\hline First Grade & Second Grade \\
\hline subsidence & $\begin{array}{l}\text { cumulative subsidence quantity } \\
\text { subsidence rate } \\
\text { radius curvature }\end{array}$ \\
\hline convergence & $\begin{array}{l}\text { change rate } \\
\text { cumulative convergence variable }\end{array}$ \\
\hline geological environment & $\begin{array}{l}\text { topography } \\
\text { across the sand layer } \\
\text { across the clay layer }\end{array}$ \\
\hline structural percolating water & $\begin{array}{l}\text { water mud sand ratio } \\
\text { infiltration rate } \\
\text { infiltration aquare }\end{array}$ \\
\hline
\end{tabular}

2. Measures of second-emphasis prevention area of land subsidence (area I)

The existing arrangements of groundwater exploitation and recharge situation will have been optimized and the management of groundwater development and utilization along high speed railway will have been strengthened.

3. Measures of general prevention area of land subsidence (area III)

The existing arrangements of groundwater exploitation and recharge situation will have been optimized, linkage mechanism of land subsidence will have been established in the Yangtze River delta and the construction of monitoring net for the metro and the sea wall will have been improved.

\section{Application of land subsidence risk evaluation to metro safety operation}

The thinking of the risk evaluation of land subsidence can be used to evaluate the risk of specific projects subsidence. Different projects have different characteristics and different sensitive degree of land subsidence, so it is difficult to establish the vulnerability evaluation of subsidence. This paper attempts to take the metro as the breakthrough point and makes risk evaluation of metro subsidence. The results provide a basis for the deployment of daily monitoring and early warning.

\subsection{The identification of risk sources of metro}

1. Regional land subsidence

An comparison of metro subsidence and regional land subsidence shows that their overall trend is consistent (Fig. 5). The metro subsidence cone area is generally greater than regional land subsidence in a short time after the construction of metro, then metro subsidence and regional land subsidence are consistent. In recent years, metro subsidence has become alleviative along with a slow down in land subsidence growth. The soil deformation below the tunnel floor plays a crucial role in the metro tunnel subsidence, and the soil deformation above the tunnel floor has a little effect on the metro tunnel subsidence.

\section{Geological structure difference}

In the metro areas, the difference of geological structure of soil layers is large. Different engineering geological characteristics and different disturbance extent of soil layers in construction stage can obviously cause different subsidence of the metro. The soft clay layer in the ancient river cutting areas which is easy to produce deformation by the static load and dynamic load of train is usually thicker than the normal areas. Some sections 

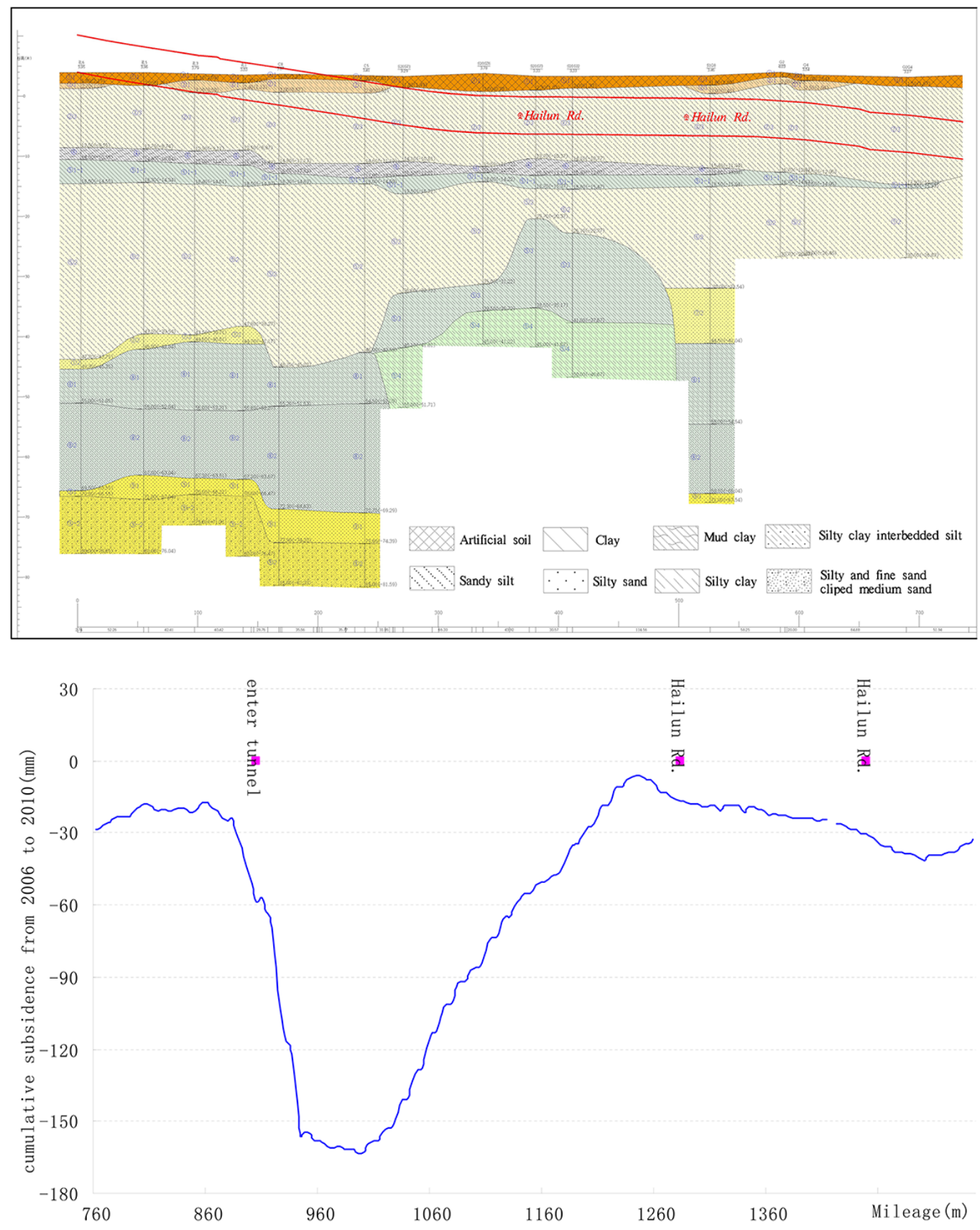

Figure 6. Engineering geological profile comparison chart of tunnel cumulative subsidence.

located in the thick sand layer can cause the large subsidence of metro because the structure of sand soil is obviously destroyed (Fig. 6).

\section{Safety inspection to metro}

The structural diseases can be found in a timely manner by rail tunnel daily inspections, such as seepage of underground structure, tube cracks, tube loss, and so on. When structural diseases are founded, they serve as the sources of risk and require more attention to the subsidence development.

\subsection{Risk evaluation indexes of metro subsidence}

Based on an thorough investigation into geological environmental characteristics and risk sources of the metro, appropriate and quantifiable indexes are selected combining with the characteristics of metro structure itself. Then the risk 


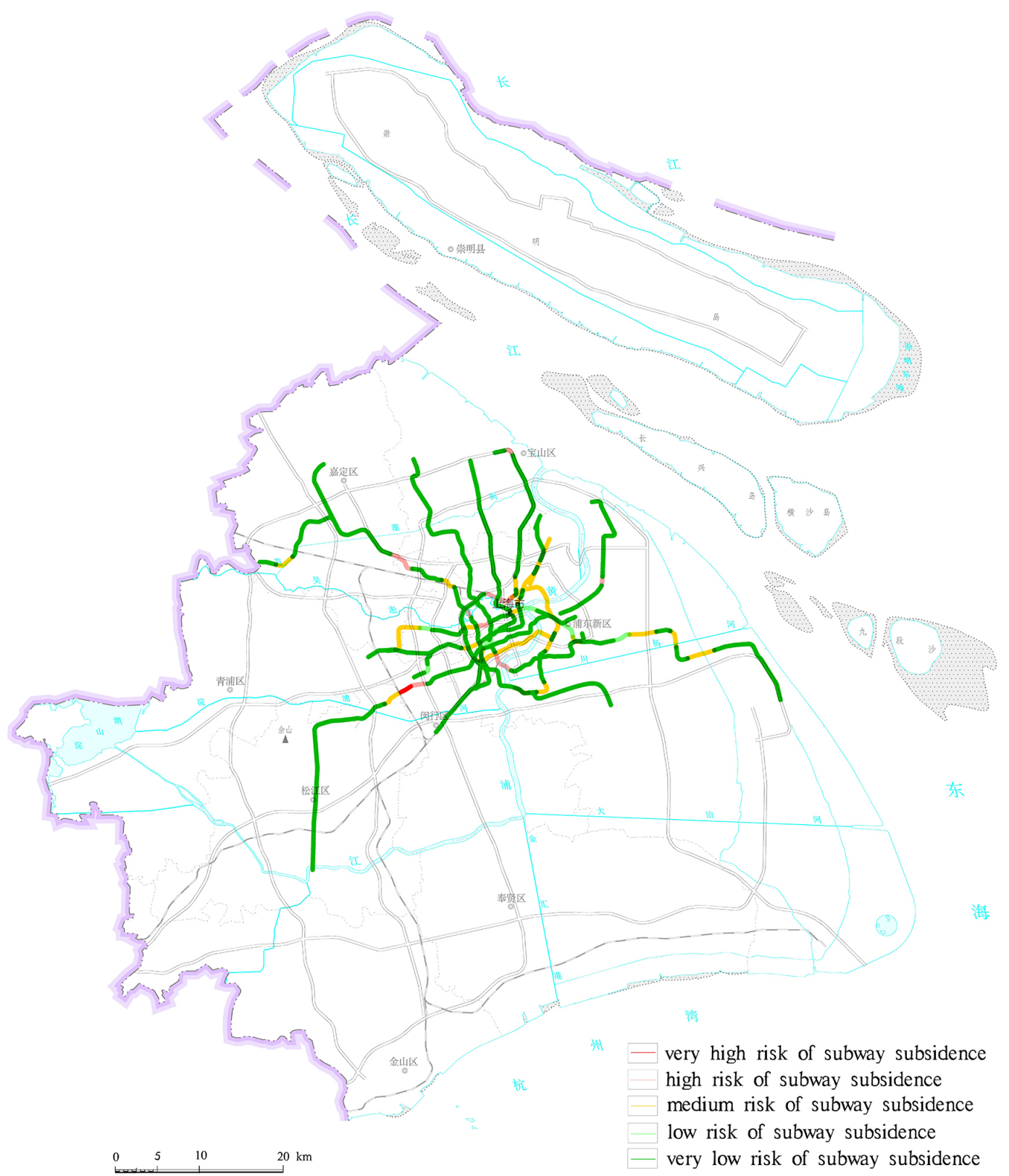

Figure 7. Risk evaluation of metro subsidence in Shanghai.

evaluation indexes system of metro subsidence is established in Table 1.

\subsection{Risk evaluation of Metro subsidence}

Based on the analysis of above-mentioned risk sources, the risk evaluation method is used to develop the risk evaluation of metro subsidence, and provide the safety precaution of metro by the evaluation results. The evaluation results show that the high risk sections of metro subsidence mainly have located in the emphasis prevention area of land subsidence (area I), as illustrated in Fig. 7. The largest risk sections lo- cated at line 4 from Baoshan road station to Helen road station which is the transition section between surface and beneath. Specifically, the uneven subsidence at line 4 near Helen road station was serious and its risk was very high. It would cause the greater harm to the metro security. Suggestions were given on strengthening monitoring and maintenance, or doing maintenance in a wide range when necessary. The above conclusion provided the technical support for an overhaul on 22 January 2012, New Year's eve. 


\section{Conclusions}

Conclusions can be drawn by the numerical experiments. (1) Using the improved fuzzy analytic hierarchy process, not only solves the problem of the consistency of judgment matrix, but also overcomes the fuzziness of the factor's weight.This method avoids the difference of risk evaluation results caused by human factors. (2) According to developmental characteristics and influence factors of land subsidence in Shanghai, the land subsidence risk evaluation is developed, the land subsidence prevention management areas are delimited and the corresponding prevention measures are adopted. The policy and social behavior of disaster management mode under the government guidance can be realized. (3) Based on the recognition of risk sources on the metro in Shanghai, the paper builds the risk evaluation index system of metro subsidence, and applies the risk evaluation results to the daily security operation of the metro in Shanghai. Thus it can provide the technical support for daily key monitoring and early warning in the management of metro operation.

Acknowledgements. The authors thank the finacial assistances given to this work by the Science and Technology Comission of Shanghai Municipality (Funding no. 12231200700).

\section{References}

Brabb, E. E.: Innovation approaches to landslide hazard and risk mapping, Proc. 4th ISL, Torronto, 307-323, 1984.

Chen, Y., Shu, L., and Burbey, T. J.: Composite subsidence vulnerability assessment based on an index model and index decomposition method, J. Human Ecol. Risk Assess., 19, 674-698, 2013.

Chen, Y., Shu, L., and Burbey, T. J.: An integrated risk-assessment model of township-scaled land subsidence based on an evidential reasoning algorithm and fuzzy set theory, Risk Analysis, 34, 656-669, 2014.

Csutora, R. and Buckley, J.: Fuzzy Hierarchical Analysis: the Lambda-Max Method, Fuzzy Set. Syst., 120, 181-195, 2001.

Feng, K.: A New Fuzzy Hierarchical Analysis Method Based on the Ideal Alternative. Proceedings of the Six International Conference On Machine Learning and Cybernetics, Hong Kong, 1922, 2007.

Hu, B., Jiang, Y., and Zhou, J.: Assessment and zonation of land Subsidence disaster risk of Tianjin binhai area, Sci. Geogr. Sin., 28, 693-697, 2008.

Woude, S. V. and Jonker, J. H.: Risk management for the Betuweroute shield driven tunnels, $(\mathrm{Re})$ Claiming the Underground Space, 1043-1049, 2003.

Yoo Chungsik, Y.-W. and Choi, B.-S.: IT-based tunneling risk management system (IT-TURISK) - Development and implementation, Tunneling and Underground Space Technology, 21, 190202, 2006.

Yu, J., Wu, J., and Wang, X.: Preliminary research on risk of land subsidence, Geol. J. China Universit., 14, 450-454, 2008. 